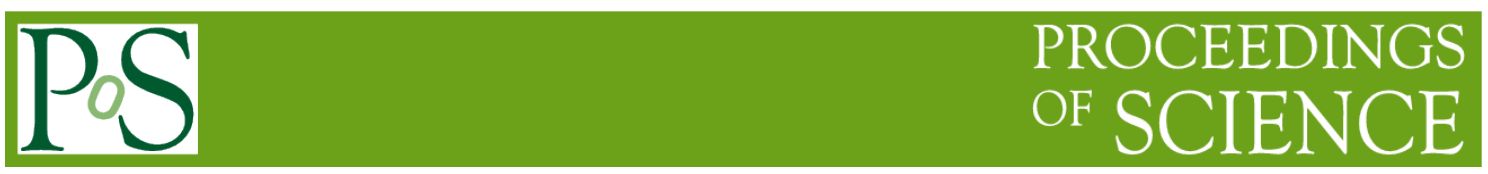

\title{
Green Suppliers Evaluation by Fuzzy Clustering and TOPSIS Suppliers
}

\author{
Mingwei Zhang' \\ School of management, Shanghai University \\ Shanghai, 200444, China \\ Email: zmw_shuesina.com
}

According to the concept of green supply chain, in this paper, we introduce a multi-method multiple criteria approach to develope more appropriate green supplier programs and practices. In reality, investigation into this field of study has just begun. We propose a combination of new fuzzy clustering means (FCM) better than the traditional clustering method and technique for order of preference by similarity to ideal solution (TOPSIS) approaches for different suppliers' performance evaluation and their relationship with business, organizational attributes and performance outcomes, identifying a sets of guidelines that help make investment more judicious and efficient. Practical research implications of this work are shown in detail in the paper. Although the intention of methodology results from sustainability concerns, this method can also be applied in other areas where making decisions is based on a large sets of data.

CENet2017

22-23 July, 2017

Shanghai, China

${ }^{1}$ Speaker 


\section{Introduction}

Traditional researches and practices on the supply chain management mainly focus on the optimization as well as coordination of supply chain, but negelect the negative impact on the environment such as resource depletion and natural pollution. However, modern green supply chain management containing both supply chain and environment management is thus dedicated to taking economic and social benefits into account at the same time [1,2]. The process of implementing sustainable supply chain is complicated because it involves interactions within and between organizations [3]. The development of green suppliers is the critical factor in fulfilling the green supply chain management $[4,5,6]$. One of the most difficult issues is how to allocate limited capital and resources to technology, training, research and development, knowledge transfer, etc. Therefore, selecting relatively appropriate programs calls for multifaceted thinking. In order to solve this problem, we introduce a formal method utilizing FCM [7,8,9] and TOPSIS [10] to aid organizations evaluate and rank the performance of various programs and practices provided by environment suppliers. Two methodologies' strong points are integrated to rank data objects based on different attributes. The combined method decreases the computational difficulties since it divides the work into two parts. First, FCM algorithm is used to cluster several programs and practices based on the general characteristics. Then TOPSIS is to develop sequence of the clusters and rank objects within the clusters.

Recently, supply chain management has become a matter of concern due to the environmentburdens. For instance, more than 800 executives discovered that supply chain management was the main barrier to the improvement of cooperate sustainability [11]. More emphasis has now been put on this domain, which resulted in practical and theoretical development of green supply chain management (GSCM), such as empirical studies, case analysis theory and mathematical and analytical modeling [12].

To begin with, we have to clearly understand what is GSCM. GSCM is a modern environmental sustainability concept, offering an expanded perspective on environmental management that includes programs and practices adopted inside and outside the corporations. There is no denying that the performance level of environmental management is closely related to the adoption of green programs and practices, like green logistics, environmental purchasing, sustainable management, etc. Table1 lists many possible works on GSCM. Nevertheless, most companies do not have enough capitals and resources to invest in the activities listed and for a company, the main task is to make profits and maintain the organization. As a result, the selection of programs can be treated as a multiple objective decision-making (MODM) problem. Supply chain managers and decision makers have to face a great number of uncertain programs and practices associated with multiple attributes and targets like commercial profitability, organizational expansion, employee satisfaction, etc. Many approaches existed for MODM [13]. In this article, we will combine Fuzzy-C Means with TOPSIS to classify clusters and objects in them.

The paper is organized as follows. The paper begins with literature research about GSCM in terms of investment and evaluation of green supplier development practices and MODM that used to consider efficient programs. Then, a brief literature review of two methodologies is introduced. An illustrative, hypotheticalexample is provided and an illustrative application of the approach is presented. Finally, the paper concludes with a summary of insights, limitations as well as the future direction . 


\section{Notion about Fuzzy-C Means and TOPSIS}

Before we use these two combined approaches, some simple notion about FCM and TOPSIS will be explained.

\subsection{Overview of Fuzzy-C Means}

FCM is one special type of clustering analysis. It is the idea of basic fuzzy clustering. FCM solves the drawbacks of traditional clustering such as K-means and hierarchical clustering twhere only two discrete values, 1 and 0 , is used to define whether a object belong to a unique group. Hard clustering requires absolute boundaries between clusters, so it can not tackle many real world problems. FCM is a method to group similar data objects into different clusters based on membership grade. Thus, objects in one cluster are more similar to each other, meanwhile data objects in different clusters share little resemblance. The degree of membership in the fuzzy clusters depends on the closeness of the data objects to the cluster centers and is quantified by a value in the interval $[0,1]$. A higher degree of membership value represents greater association between that object and a particular cluster. This clustering of data objects is achieved by iteratively minimizing an objective function that is a function of the sum of distances between the objects in a cluster and the center of that cluster.

The advantage of FCM can be summarized as more robust distance measurement for clustering capable to cluster more generally shaped datasets and can achieve result with less calculations and iterations than other cluster model [14].

Fuzzy C-Means (FCM) algorithm attempts to partition objects $X=\left\{x_{1}, x_{2}, \cdots, x_{n}\right\} \in R$ into a collection of $c(1<c<n)$ fuzzy clusters with $V=\left\{V_{1}, V_{2}, \ldots, V_{C}\right\}$ cluster centers or centroids. The fuzzy clustering of objectives will be put into a fuzzy matrix $U$ with $n$ rows and $c$ columns, which $n$ is the number of objects and $c$ is the number of centers. The element $u_{i k}$ in the $i$ th row and $k$ th column in $U$ implies the degree of relation or the membership that item $i$ belongs to cluster $k$.

Some rules should be listed before we use this matrix:

$$
\begin{aligned}
& u_{i k} \in[0,1], i=1,2, \cdots, n ; k=1,2, \cdots, c \\
& \sum u_{i k}=1, i=1,2, \cdots, n \\
& 0 \leqslant \sum u_{i k}=1 \leq n, k=1,2, \cdots, c
\end{aligned}
$$

The goal of FCM algorithm is to minimize the objective Function (2.4)

$$
\min J(U, V)=\sum \sum\left(u_{i k}\right)_{m}\left(\left\|x_{k}-v_{k}\right\|\right)_{A}
$$

Here $m(m>1)$, a scalar terms for the weighting exponent, controls the fuzziness of the resulting clusters. $\left(\left\|x_{k}-v_{k}\right\|\right)_{A}$ is the Euclidian distance between object $v_{i}$ and center $v_{k}$ moreover. Mahalanobis distance can replace the Euclidian distance to eliminate the influence of dimensions by replacing the $A=C-1$ ( where $C$ is the covariance matrix). The solutions of constraint optimization problem in Expression (2.4), are given in Expression (2.5) and Expression (2.6) respectively:

$$
v_{i t}=\frac{\sum\left(u_{i k}\right)_{m} x_{k}}{\sum\left(u_{i k}\right)_{m}}, i=1,2, \cdots, c
$$




$$
u_{i k t}=\left[\sum\left(\frac{\left(\left\|x_{k}-v_{(i, t-1)}\right\|\right)_{A}}{\left(\left\|x_{k}-v_{(j, t-1)}\right\|\right)_{A}}\right)^{\frac{2}{m-1}}\right], i \neq j
$$

The iteration steps of FCM algorithm are given below

Step 1. Choose suitable $c, \mathrm{~m}$ and $\varepsilon$, which is quite tricky in reality. ( $\varepsilon$ is the minimal threshold value)

Step 2. Set original cluster centers randomly.

Step 3. Iterate expression (2.5)(2.4)(2.6), from $t=1$ to T until $\left\|h_{(i, t)}-h_{(i, t-1)}\right\| \leq \varepsilon$ stop.

After FCM iteration, each data object will be related to a cluster through a membership value ranging from 0 to 1 , closed set. The higher values mean the tighter association between this object and a certain cluster. Then this object can be assigned to that cluster due to its high membership value. The limitations of FCM are that it still needs subjective selection of value $\mathrm{c}$ (the number of clusters) and $\mathrm{m}$ (the order of fuzziness), and the quality of the optimal function will be affected. For example, more clusters generate more detailed partition, which may cause over fitting. In addition, the selection of the initial cluster centers also affects the quality of clustering. In conclusion, we should continually discover how to find the suitable $c$ and index $\mathrm{m}$ objectively.

\subsection{Overview of TOPSIS}

In the next stage of MODM, TOPSIS is a method used to rank objects by the similarity to the ideal solutions. The core idea is to find a relatively satisfied object having the shortest distance from the positive solution and the farthest distance from the negative ideal solution.

The main steps are shown as follows:

Step 1. Normalize the established decision matrix $U=\left(x_{i j}\right)_{(n \times m)}$ for ranking. There are many methods to do so, such as the mean algorithm, extremal method, departure method, etc. Here we use extremal method like Expression (2.7). This step can be also be calculated before FCM.

$$
v_{i j}=\frac{x_{i j}-\min x_{i j}}{\max x_{i j}-\min x_{i j}}, i=1,2, \cdots, n ; j=1,2, \cdots, m \text {; }
$$

Step 2. Build the weighted standard decision matrix. This step may be omitted when there is no preference between different criteria.

$$
y_{i j}=w_{j} \cdot v_{i j}
$$

Step 3. Determine the positive-ideal and negative-ideal solution.

$$
\begin{aligned}
& r_{1}=\left(\text { max } y_{i j} \text { benefit attribuate }\right) \vee\left(\min y_{i j} \text { cost attribuate }\right) \\
& r_{2}=\left(\text { min } y_{i j} \text { benefit attribuate }\right) \vee\left(\max y_{i j} \text { cost attribuate }\right)
\end{aligned}
$$

Step4. Calculate the Euclidian distance between objects and $r_{1}, r_{2}$

$$
\begin{aligned}
& u_{i}^{1}=\sqrt{\left(\sum v_{i j}-v_{i j}^{+2}\right)}, i=1,2, \cdots, n \\
& u_{i}^{2}=\sqrt{\left(\sum v_{i j}-v_{i j}^{-2}\right)}, i=1,2, \cdots, n
\end{aligned}
$$

Step 5. Calculate the close degree to the ideal solution. The relative closeness of the alternative $r_{1}$ according to $r_{2}$ is defined by Expression (2.13).

$$
T_{i}=\frac{u_{i}^{1}}{u_{i}^{1}-u_{i}^{2}}
$$


Step 6. Sort the preference sequence by comparing the close degree Ti. The larger Ti is, the better objective will get. The best object is the one with greatest relative closeness to ideal solution. In reality, we rank objects by decreased order to show the best alternative clearly.

\section{Application}

After simple review of FCM and TOPSIS, we now apply them in multistage methodology to rank the performance of the different environmental, business, and organizational factors that come into play in an investment in green supplier development programs and practices.

We use an illustrative case from Bai's paperto verify our method is better than traditional one. Although we have 3 kinds of conditional attributes, 2 major program groupings and organizational characteristics. Each of them can be further disaggregated into more detailed programs and practices.

Here we use MATLAB2014b to execute the FCM function. Set 4 cluster number (c) and suppose fuzzy member $(\mathrm{m})$ equals to 2 according to the convention. From the four clusters according to the environmental programs data in Bai's illustrative example using simple FCM function, Iit reveals the degree of belonging or membership for each supplier and the 4 clusters. For example, Supplier 1 is the part of cluster 1 through 4 is $71.9 \%, 12.3 \%, 8.3 \%$ and $7.6 \%$ respectively. The maximum membership is $71.9 \%$ that means that Supplier 1 is the closest to the cluster 1 center. Suppliers in the same cluster would show the same result on the environmental performance. Table 1 displays each maximum value of membership so that we can have a clear knowledge which cluster the supplier belongs to.

\begin{tabular}{|c|c|c|c|c|}
\hline & $\begin{array}{c}\text { Distance from } \\
\text { the best solution }\end{array}$ & $\begin{array}{c}\text { Distance from } \\
\text { the worst } \\
\text { solution }\end{array}$ & $\begin{array}{c}\text { Closeness } \\
\text { coefficient }\end{array}$ & Rank \\
\hline Cluster 1 & 0.45889 & 0.96757 & 0.678302 & 1 \\
\hline Cluster 2 & 0.70231 & 0.63452 & 0.474645 & 2 \\
\hline Cluster 3 & 0.97871 & 0.32677 & 0.250306 & 4 \\
\hline Cluster 4 & 0.98778 & 0.35666 & 0.265285 & 3 \\
\hline
\end{tabular}

Table 1:Ranking of 4 Clusters by TOPSIS for the Environmental Factors

In the next stage, we will consider the ranks of 4 clusters based on whether they do good to the environment. Table1 shows the coefficient by using of TOPSIS algorithm for the environmental criteria. In this stage, we first calculate the Euclidian distance between benefit (best) point and cost (worst) point, then use Expression 13 to get the relative closeness. Conclusively, cluster 1 has the highest position comparing to other 3 clusters, therefore, suppliers belonging to cluster 1 may have the better performance than the other suppliers because they are closer to the best solution. Similarly, we use TOPSIS to calculate the ranking of suppliers within 4 clusters and the outcome is shown in Table 2. Upon data analysis, we find that Supplier 1, 9 and 22 would achieve environmental-friendly result in the end. 


\begin{tabular}{|c|c|c|c|c|c|c|c|c|c|c|c|}
\hline & Supplier & $\begin{array}{c}\text { Distance } \\
\text { from the } \\
\text { best } \\
\text { solution }\end{array}$ & $\begin{array}{c}\text { Distance } \\
\text { from the } \\
\text { worst } \\
\text { solution }\end{array}$ & $\begin{array}{c}\text { Closenes } \\
\text { s } \\
\text { coefficie } \\
\text { nt }\end{array}$ & Rank & & Supplier & $\begin{array}{c}\text { Distance } \\
\text { from the } \\
\text { best } \\
\text { solution }\end{array}$ & $\begin{array}{c}\text { Distance } \\
\text { from the } \\
\text { worst } \\
\text { solution }\end{array}$ & \begin{tabular}{|c|} 
Closenes \\
s \\
coefficien \\
$t$
\end{tabular} & Rank \\
\hline \multirow{10}{*}{ Cluster 1} & Supplier 1 & 0.287 & 0.333 & 0.5371 & 1 & \multirow{10}{*}{ Cluster3 } & Supplier 4 & 0.212 & 0.5 & 0.7019 & 2 \\
\hline & Supplier 8 & 0.387 & 0.243 & 0.3857 & 6 & & Supplier 5 & 0.423 & 0.312 & 0.4244 & 7 \\
\hline & Supplier 9 & 0.412 & 0.281 & 0.4055 & 5 & & Supplier 10 & 0.194 & 0.59 & 0.7526 & 1 \\
\hline & Supplier 14 & 0.367 & 0.333 & 0.4757 & 2 & & Supplier 11 & 0.567 & 0.213 & 0.2733 & 10 \\
\hline & Supplier 16 & 0.457 & 0.239 & 0.3434 & 9 & & Supplier 12 & 0.545 & 0.275 & 0.3356 & 9 \\
\hline & Supplier 20 & 0.471 & 0.212 & 0.3104 & 10 & & Supplier 19 & 0.454 & 0.365 & 0.4459 & 5 \\
\hline & Supplier 22 & 0.342 & 0.29 & 0.4589 & 3 & & Supplier 21 & 0.253 & 0.522 & 0.6737 & 3 \\
\hline & Supplier 23 & 0.42 & 0.249 & 0.3722 & 8 & & Supplier 24 & 0.631 & 0.334 & 0.3461 & 8 \\
\hline & Supplier 25 & 0.389 & 0.302 & 0.437 & 4 & & Supplier 29 & 0.345 & 0.444 & 0.563 & 4 \\
\hline & Supplier 28 & 0.46 & 0.281 & 0.3792 & 7 & & Supplier 30 & 0.432 & 0.323 & 0.4278 & 6 \\
\hline \multirow{5}{*}{ Cluster2 } & Supplier 2 & 0.345 & 0.721 & 0.6764 & 2 & \multirow{5}{*}{ Cluster4 } & Supplier 3 & 0.432 & 0.298 & 0.4082 & 3 \\
\hline & Supplier 6 & 0.41 & 0.614 & 0.5996 & 3 & & Supplier 15 & 0.341 & 0.434 & 0.56 & 2 \\
\hline & Supplier 7 & 0.733 & 0.281 & 0.2771 & 5 & & Supplier 18 & 0.554 & 0.212 & 0.277 & 4 \\
\hline & Supplier 13 & 0.542 & 0.601 & 0.5258 & 4 & & Supplier 26 & 0.245 & 0.502 & 0.672 & 1 \\
\hline & Supplier 17 & 0.21 & 0.803 & 0.7927 & 1 & & Supplier 27 & 0.632 & 0.211 & 0.2504 & 5 \\
\hline
\end{tabular}

Table 2: Ranking of 4 Clusters by TOPSIS for the Environmental Factors

Repeating the above, we get complete and synthetic ranks of all 3 criteria (environment, finance and organization) of 30 suppliers by TOPSIS. The final result shown in Table 3 is based on the weighted harmonic mean, which provides math mean for the position. The final ranks show the strengths and weaknesses of different suppliers. In reality, the supply chain managers can choose those suppliers who can solve specific problems in the organization. For instance, if the companies aim to reduce the environment pollution and achieve the goal of sustainable development, they would choose Supplier 1, 14, 22 and 25, which perform well in environment management. Similarly, if the companies pay more emphasis on other criteria or all the factors, they would choose corresponding suppliers according to their corporations' goal, organizational current situation, government requestand market status, etc.

\begin{tabular}{|c|c|c|c|c|c|c|c|c|c|}
\hline \multirow[b]{2}{*}{ Supplier } & \multicolumn{3}{|c|}{ factors } & \multirow{2}{*}{$\begin{array}{c}\text { Overall } \\
\text { Ranking }\end{array}$} & \multirow[b]{2}{*}{ Supplier } & \multicolumn{3}{|c|}{ factors } & \multirow{2}{*}{$\begin{array}{r}\text { Overall } \\
\text { Ranking }\end{array}$} \\
\hline & $\begin{array}{c}\text { Environ- } \\
\text { mental }\end{array}$ & $\begin{array}{c}\text { Busine } \\
\text { ss }\end{array}$ & $\begin{array}{c}\text { Organiza- } \\
\text { tional }\end{array}$ & & & $\begin{array}{c}\text { Environ- } \\
\text { mental }\end{array}$ & Business & $\begin{array}{c}\text { Organiza } \\
\text {-tional }\end{array}$ & \\
\hline Supplier1 & 1 & 2 & 4 & 1 & Supplier16 & 9 & 16 & 28 & 15 \\
\hline Supplier2 & 12 & 5 & 10 & 6 & Supplier 17 & 11 & 17 & 8 & 8 \\
\hline Supplier3 & 28 & 26 & 21 & 29 & Supplier 18 & 29 & 7 & 20 & 18 \\
\hline Supplier4 & 17 & 10 & 13 & 10 & Supplier19 & 26 & 6 & 14 & 13 \\
\hline Supplier5 & 22 & 27 & 11 & 22 & Supplier20 & 20 & 20 & 18 & 21 \\
\hline Supplier6 & 13 & 14 & 30 & 19 & Supplier2 1 & 18 & 9 & 12 & 9 \\
\hline Supplier7 & 15 & 19 & 29 & 23 & Supplier22 & 3 & 4 & 1 & 3 \\
\hline Supplier8 & 6 & 25 & 22 & 15 & Supplier23 & 8 & 22 & 5 & 7 \\
\hline Supplier9 & 5 & 1 & 3 & 4 & Supplier24 & 26 & 18 & 19 & 23 \\
\hline Supplier 10 & 16 & 28 & 7 & 14 & Supplier25 & 4 & 8 & 6 & 5 \\
\hline Supplier11 & 25 & 29 & 17 & 28 & Supplier26 & 16 & 12 & 15 & 11 \\
\hline Supplier12 & 24 & 15 & 25 & 25 & Supplier27 & 30 & 11 & 16 & 19 \\
\hline Supplier13 & 14 & 21 & 9 & 12 & Supplier28 & 7 & 23 & 23 & 15 \\
\hline Supplier14 & 2 & 3 & 2 & 1 & Supplier29 & 19 & 24 & 26 & 27 \\
\hline Supplier15 & 27 & 13 & 27 & 26 & Supplier30 & 21 & 30 & 24 & 29 \\
\hline
\end{tabular}

Table 3: Ranking of All Suppliers by TOPSIS for Environmental Criteria 


\section{Summary and Conclusion}

Recently, green supply chain management has brought about wide public concern and forced organization to respond to various competitions and pressure from both public and governments. Rigorous and careful evaluation of investment in suppliers would lead to improved environment and business performance. The difficulties of decision making is to consider both inter-organizational business requirements and sustainability issues. The ideal decisions have to take all criteria into account. This paper combines both FCM with TOPSIS to help organizations make thorough and critical investments on suppliers.

An assistant instance is shown that focuses on an information system table according to the investment on environmental friendly supply chain development, business supply chain development programs and organizational factors by various suppliers. In order to make sound investment in suppliers, FCM, a clustering approach, is used to reduce the type of different suppliers. After classification, we use TOPSIS to explore the sequence of clusters and suppliers within the clusters.

This paper considers integrating FCM and TOPSIS to simplify and generate the better suppliers. Furthermore, the contribution of this paper is not only useful in sustainable suppliers development and evaluation, but also in various rigorous and complex decision-making environment. The methodology can be used for general multiple-criteria decision making as wellSuch as, location problemorganizational performance evaluation as well as strategic and operational decisions. All these fields will be fruitful in the future.

Despite these advantages, there are some limitations (disadvantages) that should be solved in the future. Firstly, the data are collected from another paper, which is a hypothetical example and the amount of data is small. Secondly, the drawback of FCM is that it is sensitive to the parameters selection because $\mathrm{c}$ and $\mathrm{m}$ are defined subjectively. At meanwhile, the value of benefit and cost attributes of TOPSIS is also given according to experts' experience. Thus, further researches on the most appropriate parameters and their sensitivity will be required. Next step may discover a better way to ensure the parameters $\mathrm{m}, \mathrm{c}$ and ideal points or change another ways to overcome the defects of combined methods.

\section{References}

[1] Walton, Steve V., R. B. Handfield, and S. A. Melnyk. The Green Supply Chain: Integrating Suppliers into Environmental Management Processes[J]. Journal of Supply Chain Management . 1998,34(1):2-11.

[2] Zhu, Qinghua, and R. P. Cote. Integrating green supply chain management into an embryonic ecoindustrial development: a case study of the Guitang Group[J].Journal of Cleaner Production. 2004,12(10):1025-1035.

[3] Kiron D, Kruschwitz N, Haanaes K, et al. Joining Forces : Collaboration and Leadership for Sustainability The growing importance of corporate collaboration and boards of directors to sustainable business[J]. MIT Sloan Management Review. Retrieved 1June, 2015.

[4] Bai, Chunguang, D. Dhavale, and J. Sarkis. Complex investment decisions using rough set and fuzzy c-means: An example of investment in green supply chains[J].European Journal of Operational Research. 2016,248(2):507-521. 
[5] Blome, Constantin, D. Hollos, and A. Paulraj. Green procurement and green supplier development: antecedents and effects on supplier performance[J].International Journal of Production Research. 2014,52(1):32-49.

[6] Govindan, Kannan, et al. Eco-efficiency based green supply chain management: Current status and opportunities. European Journal of Operational Research.2014,233(2):293-298.

[7] M. Bahar Başkır, and I. Burhan Türkşen. Enhanced fuzzy clustering algorithm and cluster validity index for human perception [J]. Expert Systems with Applications An International Journal. 2013,40(3):929-937.

[8] Wang, Peizhuang. Pattern Recognition with Fuzzy Objective Function Algorithms[J]. Siam Review. 1983,25(3):442-442.

[9] Tan, Khang Siang, and N. A. M. Isa. Color image segmentation using histogram thresholding Fuzzy C-means hybrid approach. Pattern Recognition.2011,44(1):1-15.

[10] Büyüközkan, Gülçin, and G. Çifçi. A novel hybrid MCDM approach based on fuzzy DEMATEL, fuzzy ANP and fuzzy TOPSIS to evaluate green suppliers[J].Expert Systems with Applications. 2012,39(3):3000-3011.

[11] Hayward, Rob, et al.The UN Global Compact-Accenture CEO Study on Sustainability 2013[J].Un Global Compact Reports.2013,5(3):1-60.

[12] Brandenburg M, Govindan K, Sarkis J, et al. Quantitative models for sustainable supply chain management: Developments and directions[J]. European Journal of Operational Research.2014233(2):299-312.

[13] Guitouni, Adel, and J. M. Martel. Tentative guidelines to help choosing an appropriate MCDA method [J]. European Journal of Operational Research.1998,109(2):501-521.

[14] Ramathilagam, S., and Y. M. Huang. Extended Gaussian kernel version of fuzzy c-means in the problem of data analyzing[J]. Expert Systems with Applications. 2011,38(4), 2011:3793-3805. 